\title{
Job Satisfaction Challenges Of Nurses In The Intensive Care Unit: A Qualitative Study
}

This article was published in the following Dove Press journal:

Risk Management and Healthcare Policy

\author{
Somayeh Mousazadeh' \\ Shahrzad Yektatalab ${ }^{2}$ \\ Marzieh Momennasab ${ }^{3}$ \\ Soroor Parvizy ${ }^{4}$ \\ 'Amol Faculty of Nursing and Midwifery, \\ Mazandaran University of Medical \\ Science, Sari, Iran; ${ }^{2}$ Community Based \\ Psychiatric Care Research Center, \\ Department of Mental Health and \\ Psychiatric Nursing, School of Nursing \\ and Midwifery, Shiraz University of \\ Medical Sciences, Shiraz, Iran; \\ ${ }^{3}$ Department of Nursing, School of \\ Nursing and Midwifery, Shiraz University \\ of Medical Sciences, Shiraz, Iran; \\ ${ }^{4}$ Department of Pediatric Nursing, \\ Nursing and Midwifery Faculty, Center \\ for Educational Research in Medical \\ Sciences (CERMS), Iran University of \\ Medical Sciences, Tehran, Iran
}

Background: Job satisfaction is an important factor in health care settings. This concept is not a single factor; rather, it is the product of factors such as the conditions and relationships that govern the workplace, the organizational system of employment, and social, cultural, and economic factors. Therefore, awareness of its related factors is important for medical staff including nurses in special units and nursing managers. The aim of the present study was to investigate job satisfaction challenges in intensive care unit (ICU) nurses.

Methods: This was a qualitative study using conventional content analysis approach. This study was performed in a general ICU of Amol City, Iran. Thirteen nurses employed in the ICU were recruited until data saturation was reached. Research data were collected through interviews, a focus group and field notes. Findings were analyzed using a conventional method.

Results: According to data analysis, 6 themes including "nursing education", "organizational resources", "management", "multiple occupational stresses", "professional performance" and "professional identity" were developed.

Conclusion: This study provided better and clearer understanding of job satisfaction challenges of nurses working in an ICU. The findings of this research can be helpful in developing management programs for understanding the factors affecting job satisfaction of nurses and job satisfaction promotion.

Keywords: job satisfaction, nurses, intensive care unit, ICU

\section{Introduction}

Job satisfaction is one of the important factors in medical health system staff. At least $50 \%$ of health services are provided by the nurses, and even in some countries, $80 \%$ of health affairs are done by the nurses. Thus, their satisfaction influences the organizational success and quality of health care. ${ }^{1}$

Lack of job satisfaction in the long term disrupts the organization and causes rebellion, absenteeism, and reduced sense of responsibility and commitment of nurses. ${ }^{2}$

Also, dissatisfaction with job leads to medical and nursing errors, and other undesirable functioning.

On the other hand, increasing job satisfaction causes higher efficiency and a feeling of satisfaction with one's self. Individuals who feel satisfied with their job are more likely to stay in their job. ${ }^{2}$

Nurses employed in the hospital, especially in the ICU, struggle with different issues such as, job features, workload, high level of physical, mental, and emotional stress in the workplace which may affect their job satisfaction, and they are mostly dissatisfied with their job. ${ }^{3}$
Correspondence: Shahrzad Yektatalab Community Based Psychiatric Care Research Center, Department of Mental Health and Psychiatric Nursing, School of Nursing and Midwifery, Shiraz University of Medical Sciences, Zand Blv, Namazi Square, Shiraz 71936-13119, Iran Tel +987136474254

Email Yektash@sums.ac.ir 
Therefore, determining factors which may affect the dissatisfaction of nurses working in these units is important. Findings of studies in western countries are not so applicable in Asian countries such as Iran because of cultural. ${ }^{4}$ Thus, based on the review of literature and lack of studies, job satisfaction challenges in Iranian nurses, especially ICU nurses, the current study was conducted in order to describe job satisfaction challenges in these nurses.

\section{Methods}

\section{Participant And Research Context}

Research participants included 13 nurses employed in ICU in the hospital affiliated to Mazandaran University of Medical Sciences. Purposive sampling is suitable for qualitative studies where the researcher is interested in individuals who have the best knowledge or experience concerning the research topic or realm of interest. ${ }^{5}$ In addition to knowledge and experience, the importance of availability and willingness to participate, and the ability to communicate experiences and opinions in an articulate, expressive, and reflective manner are mentioned as other criteria for entering the study. ${ }^{6}$ Participants were in the city of Amol (located in north of Iran) affiliated to Mazandaran University of Medical Sciences. The hospital has two ICU wards, neurology ICU and Surgery ICU. Neurologic ICU was chosen as the research setting because of its specific condition due to the work environment, the patients' poor condition with low level of consciousness and dependence as well as workload that altogether make nurses susceptible to stress and dissatisfaction. Inclusion criteria were availability, minimum of 1 year working in ICU, willingness to take part in the study.

\section{Data Collection}

The study was conducted using descriptive exploratory qualitative design with a content analysis approach. Triangulation of time (different shifts), person (adolescents from different age groups and both sexes) and data gathering with interviews, focus group and field notes were done. Triangulation refers to the use of multiple methods or data sources in qualitative research to develop a comprehensive understanding of the phenomena. ${ }^{7}$

For this purpose, according to inclusion criteria, the researcher informed the participants 3 days prior to the interview, and if desired, the time and place of the interview was determined by them, and the day before the interview, the necessary coordination was made with them. Participants were interviewed in the staff room to maintain their safety and convenience and to freely express their experiences and thoughts. The first author (S.M.) arranged and conducted all the interviews with the participants. The interviews were recorded and immediately transcribed verbatim. In the individual interviews, data were collected from each participant in one session, 13 in-depth semi-structured interviews were conducted with the ICU nurses, who were selected through a purposeful sampling, and sampling was continued until saturation was reached. A pamphlet was prepared for the key questions that were general with prompts to encourage responses during the interviews. Examples of interview questions are available in Appendix 1.

Interview started with general questions and then more specific questions were asked, such as "Can you explain more? What do you mean? Can you explain your personal experience with an example? Why? How?" These questions were raised in order to achieve research objectives and based on responses of the participants for clarifying details.

Each interview lasted about 35-90 mins and all the interviews were recorded. Also, two sessions for focus group including 5 to 6 people were run within 95 to 120 mins with nurses who did not want to have an individual interview, and other nurses who were willing to participate in group discussions. Group discussion started with such questions as "What is your idea about job satisfaction? Express your job satisfaction challenges". With initiation of discussions by participants, the parts related to the research subject were encouraged by the researcher in order to motivate others to take part in the discussion. During the interview, exploratory questions were used in order to deepen the discussions so that it was finally clear which factors, who, and how and under which conditions, influence job satisfaction of nurses.

\section{Data Analysis}

After data collection, the conventional content analysis was done using Graneheim and Lundman's method. ${ }^{8}$ We had used latent analysis that is extended to an interpretive level in which the researcher seeks to find the underlying meaning of the text. It allows the researcher to immerse himself or herself, to some extent, in the data in order to identify hidden meanings 
in the text ${ }^{9}$ Because our participants are adolescents, latent analysis helps us to explore the hidden meanings. There is little information about nurse's job satisfaction challenges and so content analysis as a systematic method of generating new knowledge about perceptions and feelings was the best method. ${ }^{8,10}$ The recorded and transcribed interviews were read several times to ensure the in-depth and overall understanding. According to the units of analysis, which was the whole body of the interviews, the texts were divided into condensed meaning units such as words, sentences, or paragraphs containing aspects related to each other through their content. Then, each condensed unit was labeled with a code. Then, different codes were compared based on the relationship of underlying meanings, and the same meanings were categorized together, which formed sub-categories. The sub-categories were combined to create categories that were based on the adolescents' expressions and the qualitative content of their meaning. Finally, 15 sub-categories and four main themes were formed with agreement of the researchers. ${ }^{6}$ Data analysis was done concurrently with data collection and data collection continued until saturation was achieved, that is, adding more data did not reveal new information and was thus redundant. ${ }^{8}$ Data analysis was carried out using the One Note software2013 and manual method.

\section{Rigor}

In order to ensure trustworthiness, Lincoln and Guba's criterion was used. ${ }^{11}$ At the beginning of the study, the researchers bracketed all their prior information and personal beliefs regarding maintaining dignity in the care setting in order to avoid the influence and interference of personal beliefs in the investigation of this phenomenon. To increase the reliability and validity of findings, several techniques were employed including combining review of data sources (semi-structured interviews and field notes), prolonged engagement with the data, member checking, and peer checking. To do this, the extracted concepts and themes were submitted to four participants and two peers who stated that the findings were in line with their understandings and interpretations. Furthermore, the researcher limited the textual reviews in order to reduce bias in collecting, analyzing, and coding of the interviews to increase the validity of the data. Finally, confirmability was acquired through exact recording of participant narratives and detailed reporting of the study to provide the possibility of follow-up for other researchers.

\section{Ethical Considerations}

The ethics committee of the Shiraz University of Medical Sciences approved the project (number: ir.suns.rec. 1395. s1092). It should be noted that before each interview, the study's aim, reasons for recording interviews, voluntary participation, and confidentiality of data and interviewees were explained to the participants, and written informed consents were obtained. The time and place of the interviews were then arranged with them and they were given the researcher's details and a method of access to the research results. Besides, they were told that they could withdraw from the study at any time they wished.

\section{Results}

Research participants were 13 nurses, who had a mean age of $32.95 \pm 6.27$ years with a range of $23-50$ years. The majority of them were female (71\%) and married (82.3\%). Most of the participants (36.3\%) had 1-5 years of work experience. Also, the majority of them $(98.4 \%)$ had BA degree. As to their employment status, $42.7 \%$ of the participants were on contract, and the working shift of $92.7 \%$ of them was as rotation work shift; $51.8 \%$ of them had 50-100 hrs of overtime work per month.

Six themes including "nursing education", "organizational resources", "management", "multiple occupational stresses", "professional performance" and "professional identity", along with 15 sub-themes were emerged from the data as shown in Table 1.

\section{Nursing Education}

From the perspective of the participants, staff education is a very strategic and important subject as the foundation for the growth and development of any organization and as a key factor to the development of any organization that contributes to the dynamics of the organization. Inadequacy in nursing education, such as ineffective methodologies, inappropriate course contents and improper timing are among the challenges regarding job satisfaction.

\section{Ineffective Methodologies}

Some participants explained this situation to emphasize the educational content delivery in traditional manner. They maintained that the content delivery using lecture method is mostly focused in their education, which is 
Table I Main Themes And Categories Of Job Satisfaction Challenges In ICU Nurses

\begin{tabular}{|c|c|c|}
\hline \multirow{16}{*}{$\begin{array}{l}\text { Nurses job } \\
\text { satisfaction } \\
\text { challenges }\end{array}$} & Themes & Sub-Themes \\
\hline & \multirow{3}{*}{$\begin{array}{l}\text { Nursing } \\
\text { education }\end{array}$} & Ineffective methodologies \\
\hline & & Inappropriate course contents \\
\hline & & Improper timing of education \\
\hline & \multirow{3}{*}{$\begin{array}{l}\text { Organizational } \\
\text { resources }\end{array}$} & Lack of recreational facilities \\
\hline & & $\begin{array}{l}\text { Qualitative and quantitative } \\
\text { inefficiency of human } \\
\text { resources }\end{array}$ \\
\hline & & Lack of proper equipment \\
\hline & \multirow[t]{2}{*}{ Management } & $\begin{array}{l}\text { Lack of knowledge and skill in } \\
\text { management }\end{array}$ \\
\hline & & $\begin{array}{l}\text { Lack of clinical knowledge and } \\
\text { skill }\end{array}$ \\
\hline & \multirow{3}{*}{$\begin{array}{l}\text { Multiple } \\
\text { occupational } \\
\text { stresses }\end{array}$} & High stress working in ICU \\
\hline & & $\begin{array}{l}\text { Stressful nature of the nurses' } \\
\text { work schedule }\end{array}$ \\
\hline & & Excessive work load \\
\hline & \multirow[t]{2}{*}{$\begin{array}{l}\text { Professional } \\
\text { performance }\end{array}$} & $\begin{array}{l}\text { Ineffective professional } \\
\text { interactions }\end{array}$ \\
\hline & & Defect in moral care \\
\hline & $\begin{array}{l}\text { Professional } \\
\text { identity }\end{array}$ & $\begin{array}{l}\text { Not paying attention to nurse's } \\
\text { professional status }\end{array}$ \\
\hline & & $\begin{array}{l}\text { Distrust in the nurses' } \\
\text { knowledge }\end{array}$ \\
\hline
\end{tabular}

ineffective, and have raised it as one of the main educational challenges.

In the education for nurses, mostly a lecturer talks and others sit and listen to him. New motivating methods are not used at all. (participant number 12 [P12])

\section{Inappropriate Course Contents}

From the participants' point of view, the content of the educational course should be practical, without duplication of educational headlines and new content be taught each time as well.

We have to take part in classes which are not useful for us at all, because they have some prepared headlines, and they have to plan on them. Most of the time, the educational lectures which are given to us do not work for us. (focus group number 1 [FG1])

\section{Improper Timing Of Training Sessions}

Short educational sessions and holding classes at the right time can have a significant impact on education. But one of the educational challenges presented in this study was the inappropriate timing of educational programs.

There are some occasions when you are working in the unit; your patient is in a bad condition, but you are told that you have to attend the educational course. I wonder whether I should go or not; if I go, my patient is left alone, which is not acceptable to me. That is, my time does not match with the course being held. (FG2, P4)

\section{Organizational Resources}

Participants stated that organizational resources are facilitators in the workplace that increase motivation and satisfaction. They mentioned, that inadequate organizational resources such as lack of recreational facilities, qualitative and quantitative inefficiency of human resources, and lack of proper equipment factors are the influential factors on their job satisfaction.

\section{Lack Of Recreational Facilities}

From the nurses' point of view, having appropriate recreational facilities is an important factor affecting their job satisfaction.

Our hospital is very poor in terms of welfare facilities, the most important part of which is a kindergarten, which there isn't any here. (P3)

\section{Qualitative And Quantitative Inefficiency Of Human Resources}

Having sufficient human resources with high clinical experience and high professional knowledge can be significant in job satisfaction.

We have a shortage of human resources in ICU wards, especially in the afternoon shifts, that, according to the number of beds, each requires at least 5 nurses. But there are 4, regardless of assistants and service workers, the number of which is also low. (FG1, P2, P12)

Many of the coworkers who enter ICU either do not have experience of working in ICU, or even worse, they do not have clinical work experience at all. (FG2, P10)

\section{Lack Of Proper Equipment}

The availability of modern and adequate equipment is one of the essentials of providing useful care and the lack of 
equipment can lead to work disruptions, delays, lack of care and emotional exhaustion.

Once I wanted to take an ECG for a patient. I saw that the ECG device didn't work. It bothered me so much. It took about half an hour for something that should last 5 minutes and you do not trust it. (P7)

\section{Management}

According to participants, different managerial practices have a direct impact on their satisfaction. Managers who improve group communication and promote positive emotions in the workplace lead to more effective employee activities as well as improved job satisfaction. Participants also stated that receiving appropriate feedback from the organization as a factor affecting their satisfaction. They noted one of the important factors in inefficient management is lack of knowledge and skill in management and lack of clinical knowledge and skill.

\section{Lack Of Knowledge And Skill In Management}

Managers "managerial skills and management knowledge have a direct impact on nurses" satisfaction. Managers who have an authoritarian management style are less satisfied with adopting a collaborative management style.

In our workplace, managers highly practice discrimination. For example, if something is done against their rules and it is committed by someone whom they like, they do not counteract it, or they behave normally. But if they do not like someone, they respond in the worst manner; that is, it seems regulations are not the same for all. (FG2, P3)

\section{Lack Of Clinical Knowledge And Skill}

Nursing managers with clinical experience and therapeutic knowledge and skills are the main factors that can affect nurses' job satisfaction, while the participants of this study reported lack of clinical knowledge and skills of managers.

Once one of my patients got worse. We were all at his bed. One of the nursing authorities was also present. We intubated the patient and he had to be connected to a ventilator, but the ventilator had previously been turned on and it was sounding an alarm because it was not connected to the patient. It was really annoying. That person was also beside the ventilator and I said, pardon me, and please turn off the alarm. She looked at me for a moment and then said: which button shall I press to turns off the alarm? (P6, P12)

\section{Multiple Occupational Stresses}

From the participants' perspective, nursing is one of the most stressful jobs. Because working with patients is inherently stressful. On the other hand, the concept of job satisfaction in nursing is associated with job stress. Because stressors are common and unavoidable in the nursing workplace. This theme was extracted from categories of excessive stress in ICU, stressful nature of the nurses' work plan, and unbalanced work load.

\section{Stressful Working In ICU}

The ICU is more stressful compared to other wards. High mortality, high workload, high liability are some of the factors that increase work stress in this sector.

The majority of patients referring to this hospital die. When we see this, we feel stressful. That is, I always feel the shadow of death in the ICU, and this feeling of the closeness of death makes me stressful. ICU means the permanent presence of death. (P11, P12)

\section{Stressful Nature Of The Nurses' Work Schedules}

Nurses' work schedules play an important role in their satisfaction. Inflexible Nurses' work schedules, working with inexperienced people, as well as working day off, are factors that lead to stress. They also noted Work experience, skill level, responsibility and commitment of coworker can have a great impact on their stress.

When our work plan is written, it seems that it is a must do thing and is not changeable. So it is stressful for us. (P2, P5, P9)

\section{Excessive Work Load}

High workloads and a large number of work shifts take nurses' energy and reduces their capability of working properly. The pressure of work has made them just a Machine, and sometimes they do not even have a short time for break.

When we arrive for the shift, we should work hard until it finishes, or the only time we have for resting is when we write down our nursing report. (FG2, P4, P1)

\section{Professional Performance}

From the nurses' point of view, professionalism is a key issue for them in providing care and in some cases, it is not evident in their performance. They noted that having effective professional communication and paying attention to professional and ethical values in caring for patients could partly reflect their professional performance. 
Weakness in professional performance was obtained from analysis of interviews with participants, which included ineffective professional interactions and defect in moral care.

\section{Ineffective Professional Interactions}

Participants were dissatisfied with their communication with the patient's companions. They said that the patient's companions were always complaining about their behavior and that nurses were recognized as bad-tempered persons.

One day when I was at work, one of the patient's companions offended me aggressively, and wanted to visit his patient out of the visiting time. I was tired, I explained to him, but he did not understand; thus, I argued with him and shouted. (P11)

\section{Defect In Moral Care}

Providing ethical care is one of the aspects of holistic care approach in nursing. Moral ethics of care is one of the effective indicators in the path of professionalization among nurses that should be developed in order to maintain nursing professional practice.

Here, the patients' companions presume that we can do the religious rituals for their patients perfectly. It is not really possible. They want us to put a Quran above their head or give specific water to patients that sometimes worsens the conditions of the patient and, moreover, the environment and the working conditions do not allow us to do so. (FG2, P3)

\section{Professional Identity}

From the perspective of the participants, having a positive and flexible professional identity is important for nurses "multiple roles in providing quality care to patients and reducing workplace stress and enhancing nurses" confidence, improving their clinical performance and job satisfaction. Therefore, improving the professional identity of nurses can be effective in their job satisfaction.

Professional identity is another extracted theme. This theme was classified in negligence to nursing profession status and distrust in the nurses' knowledge categories.

\section{Negligence To Nursing Profession Status}

Protecting human dignity is one of their basic rights. Lack of attention to the social status of the nursing profession is one of the threatening factors in this profession that should be taken into consideration.

In our country, people view nursing in such a way that you are a worker and it does not have any social reputation and here, nursing is not regarded socially prestigious. (P2, P1, FG2)

\section{Distrust In The Nurses' Knowledge}

Trusting nurses' knowledge is another important aspect of professional identity. Patient care calls for a great trust between physicians, nurses, and patients, which is not so evident in the health care system.

Doctors don't trust our knowledge; If they had, our problems would be much less. (FG2, P13)

\section{Discussion}

Improving the human resources in nursing is one of the important responsibilities of nursing managers and includes activities that are implemented to promote the competence level and increase the knowledge and awareness of nurses as well as improving the skills of nurses to provide better clinical services. ${ }^{12}$ In the current study, participants stated that inadequacy in nursing education is an important issue that affected their job satisfaction. Considering the special nature of nursing profession, it is necessary for the learners of this profession to have a real understanding of material content so that they are competent in specific clinical situations to use their learnings; using active educational methods is significantly effective in increasing deep thinking skills and stability of materials in the students' minds. ${ }^{13}$ Participatory education has the best effect on the change in nurses' performance ${ }^{14-16}$ also, learning in the workplace, which can be formal and informal, is one of the most powerful training methods; also, the workplace is one of the most appropriate teaching and learning settings. ${ }^{17}$ However, the education staff is a very strategical and important issue as the foundation for the development of any organization, which contributes to the dynamics of the organization. ${ }^{15}$ On the other hand, Organizational education activities influence employees organizational commitment and their job satisfaction. ${ }^{18}$ Organizational commitment is the same as attachment and loyalty to the goals of the organization and lack of it leads to staff absenteeism, relocation, job creation, and theft and job dissatisfaction. ${ }^{19}$ Hence, improving the human resources in nursing is one of the important responsibilities of nursing managers and includes activities that 
are implemented to improve the competence level and increase the knowledge and awareness of nurses and to improve the skills of nurses to provide better clinical services. $^{12}$

Organizational resources was the other theme obtained from research. Findings of other studies suggested a significant relationship between organizational resources, human resources and job satisfaction. ${ }^{20,21}$ An unfavorable working condition for a nurse may reduce his satisfaction, and therefore will interfere with the efforts to improve patients' satisfaction because high-quality nursing care is usually the result of high levels of job satisfaction. ${ }^{22}$

Lack of recreational-welfare facilities was another challenge of nurses' job satisfaction. Recreational facilities are places or any occasion used for entertaining activities. Recreational activities usually include fun activities or listening to music, ${ }^{23}$ People with more recreational activities were less likely to experience depression. In fact, recreational activities improve the quality of life for people and move towards a healthier life and better social relationships, however, according to experts, workplace happiness increases productivity, motivation, and job satisfaction. Feeling happy in the workplace is one of the essentials of work and the role of managers and coworkers in creating a happy environment is essential to create a happy environment in workplace. ${ }^{24}$

Quantitative and qualitative inadequacy of staff was another problem that the participants pointed out. Because the shortage of manpower is directly linked to an increase in workload. Human resources are the main providers of services in the care and treatment systems whose function is to ensure the health of people. Therefore, ensuring community health in some way requires the most appropriate use of these resources. Nurses are important as the biggest human resources of the health care organization so that care organizations cannot succeed without sufficient and efficient nurse staffing. ${ }^{25,26}$

We found in our study that proper equipment was affected by nurses' job satisfaction. Consistent with the present study, findings of another study showed that inadequate equipment leads to nurses' job dissatisfaction. ${ }^{21}$ Modern and adequate equipment is one of the essentials of providing useful care and the lack of equipment can lead to work disruptions, delays, and lack of care and emotional exhaustion. ${ }^{27}$

Another theme that emerged from the research data was management. According to the results of this study, lack of knowledge and skill in management as well as lack of clinical knowledge and skill are its sub-themes. According to Morels, different management methods have a direct impact on satisfaction of nurses. ${ }^{28}$ Atefi et al state that supportive nursing management leads to increased job satisfaction in nurses. ${ }^{29-31}$ Consistent with the results of the present study, other research results showed that there was a statistically significant relationship between leadership style and job satisfaction, and employees whose leadership style was tyrannical had less job satisfaction than those whose managerial style was participatory. ${ }^{32}$ Since managers who improve group communication and promote positive emotions in the workplace, they lead to the reinforcement of effective activities in employees as well as improved job satisfaction. ${ }^{31}$ Developing effective management skills to meet the specific challenges and programs of each organization is an urgent need in many organizations and environments. Effective management helps employees and organizations improve their performance and effectiveness. Rapid development of technology and globalization, on the other hand, reflects a process of intense competition that requires effective management in these complex environments. The characteristics and styles of effective management in culture, job satisfaction, employee productivity and ultimately the success or failure of the organization are crucial. $^{33}$

One of the factors mentioned by the participating nurses as one of the challenges of job satisfaction was multiple occupational stresses that ICU nurses face.

Among the disciplines of health, nursing is one of the most stressful jobs. Because they work with patients, which is inherently stressful. On the other hand, the concept of job satisfaction in nursing is associated with job stress. Because stressors are common and unavoidable in nursing workplace. ${ }^{27,34}$ The study by Talasaz et al showed that there was a negative significant relationship between job satisfaction of nurses and their job stress. ${ }^{35}$ To be confronted with dying patients in ICU is one of the job stresses for nurses and it reduces their job satisfaction. ${ }^{21}$ Other studies mentioned the high workload of nurses as one of the major stresses of nurses working in ICU, and stated that job stress is one of the major factors affecting the nurses' satisfaction. ${ }^{27,36}$ Hong Lu stated job stress as one of the factors predicting job satisfaction. ${ }^{3}$ Nursing is a stressful profession and nurses are constantly exposed to stress due to their sensitive professional nature in a way that stress has become a recognized component of modern nursing, ${ }^{37}$ And it has become a challenge for nursing profession. ${ }^{38}$ Because of constant encountering with patients, taking responsibility for human health, performing clinical 
processes, dealing with strangled patients and emergencies, shift work are stressful occupational factors that can reduce the quality of patient care in health care settings, especially nursing depression, fatigue at work, absenteeism and delay in work. $^{39}$

Professional performance was another factor in creating job dissatisfaction in nurses. Professional communications of nurses is one of the factors affecting their job satisfaction. ${ }^{40}$ In terms of communication aspect, a good relationship among the employees is regarded as a significant factor in creating job satisfaction, because people inherently tend to work in an environment where they are liked and belong. Findings of other studies showed that good communication with colleagues and supervisors, team work, and cooperation with doctors in decision making regarding the patient care are factors affecting job satisfaction of nurses. ${ }^{14,31}$ However, having a good professional relationship and receiving social support from both colleagues and supervisors increases the level of job satisfaction. ${ }^{14}$

Participants mentioned human spiritual aspect as one of the holistic approaches in nursing during interviews, and stated that the spiritual aspect is also as important as biological aspect. Findings of a study by Habibzadeh et al indicated that belief in Islamic values in care among nurses was one of the effective ethical considerations toward professionalism of Iranian nurses, which causes ethical motivation in nursing and these concepts should be developed for preserving nursing professional performance. ${ }^{41}$ A qualitative study was done by Wong et al in Hong Kong on the experiences of nurses in spirituality and providing spiritual care in nurses. The findings showed their worry and dissatisfaction due to lack of adequate information and skill in providing spiritual care. ${ }^{42}$ Also, another research findings suggested that two major aspects of spiritual care delivery including the promotion of service provider's spiritual dimension and awareness of cultural-spiritual interventions are necessary for meeting the needs of patients. ${ }^{43}$

One of the themes obtained from the study, which was emphasized by participants, was professional identity. Lack of attention to nursing profession by doctors, nurses, and community besides distrust in their knowledge affects the professional identity of nurse. ${ }^{44}$ The study by Chio et al showed that nursing students with positive professional identity have higher levels of job satisfaction. ${ }^{20}$ In fact, a positive professional identity is significant in accomplishing various nursing tasks such as providing qualified care services for patients and decreasing workplace stress. It also increases self-confidence and self-esteem in nurses, improves job satisfaction and better their retention in the profession. ${ }^{45}$ Also, in line with the necessity for appreciation of nurses, studies showed that nurses who are not accepted and are not appreciated, experience a higher level of depression and lower self-confidence, stress, anxiety, and dissatisfaction are increased in them. ${ }^{46,47}$ Nurses in Iran are known as doctors' assistants as they have weak social image and poor professional status. ${ }^{45}$ On the other hand, it is believed that nursing values in care systems are rarely recognized, because medical values and idols are identified as enjoying excellent and top status. Thus, nursing professional identity is shadowed by medicine. ${ }^{48}$

\section{Conclusion}

Job dissatisfaction among nurses is one of the most important factors in quitting their jobs which increases the need for more nurses, and subsequently, augments the workload of current nurses, leading to their dissatisfaction. This study provided a clearer and more comprehensive understanding of the challenges of job satisfaction in nurses working in intensive care units. Therefore, nursing directors and managers need to determine the effective factors on nurses' job satisfaction and they need to control the factors which decrease their satisfaction and take some measures to increase their job satisfaction levels. Also, they need to consider the managerial job and environmental factors in order to evaluate the effectiveness of their measures periodically to improve job satisfaction. Therefore, using the results of this research can be helpful in developing managerial programs in order to foster the factors affecting nursing job satisfaction and how it can be promoted.

\section{Disclosure}

The authors report no conflicts of interest in this work.

\section{References}

1. Heydari A, Mazloum S, Moonaghi H, Mojalli M, Shahidi L, Areshtanab H. Educational challenges ahead of nursing from the perspective of faculty members of Mashhad University of Medical Sciences. J Adv Med Edu Prof. 2013;1(4):125-128.

2. DiMeglio K, Padula C, Piatek C, et al. Group cohesion and nurse satisfaction: examination of a team-building approach. $J$ Nurs Adm. 2005;35(3):110-120. doi:10.1097/00005110-200503000-00003

3. Lu H, Barriball KL, Zhang X, While AE. Job satisfaction among hospital nurses revisited: a systematic review. Int J Nurs Stud. 2012;49(8):1017-1038. doi:10.1016/j.ijnurstu.2011.11.009

4. Mokhtar K, El Shikieri A, Rayan A. The relationship between occupational stressors and performance amongst nurses working in pediatric and intensive care units. Am J Nurs Res. 2016;4(2):34-40. 
5. Elo S, Kääriäinen M, Kanste O, Pölkki T, Utriainen K, Kyngäs H. Qualitative content analysis: a focus on trustworthiness. Sage Open. 2014;4(1):2158244014522633. doi:10.1177/2158244014522633

6. Bernard HR. Research Methods in Anthropology: Qualitative and Quantitative Approaches. Rowman \& Littlefield; 2017.

7. Carter N, Bryant-Lukosius D, DiCenso A, Blythe J, AJ N, editors. The use of triangulation in qualitative research. Oncol Nurs Forum. 2014;41:545-547. doi:10.1188/14.ONF.545-547

8. Graneheim UH, Lundman B. Qualitative content analysis in nursing research: concepts, procedures and measures to achieve trustworthiness. Nurse Educ Today. 2004;24(2):105-112. doi:10.1016/j.nedt.2003.10.001

9. Bengtsson M. How to plan and perform a qualitative study using content analysis. Nurs Plus Open. 2016;2:8-14. doi:10.1016/j. npls.2016.01.001

10. Elo S, Kyngäs H. The qualitative content analysis process. J Adv Nurs. 2008;62(1):107-115. doi:10.1111/j.1365-2648.2007.04569.x

11. Lincoln Y, Guba E. Naturalistic Inquiry. Newbury Park: Sage; 1985.

12. Dirani KM. Professional training as a strategy for staff development: a study in training transfer in the Lebanese context. Eur J Train Deve. 2012;36(2/3):158-178.

13. Kermansaravi F, Navidian A, Imani M. Nursing students' views toward quality of theoretical and clinical nursing education: a qualitative study. J Med Educ Dev. 2013;7(4):28-40.

14. Abualrub RF, Omari FH, AL RUB A, FAWZI A. The moderating effect of social support on the stress-satisfaction relationship among Jordanian hospital nurses. J Nurs Manag. 2009;17(7):870-878. doi:10.1111/j.1365-2834.2009.01007.x

15. O’Mahony TK, Vye NJ, Bransford JD, et al. A comparison of lecturebased and challenge-based learning in a workplace setting: course designs, patterns of interactivity, and learning outcomes. J Learn Sci. 2012;21(1):182-206. doi:10.1080/10508406.2011.611775

16. Pearce RS, Okwuashi LO. Lecturing versus teaching in foundation and first year mainstream chemistry. J Mod Educ Rev. 2013;3(7):568575.

17. Eslamian J, Moeini M, Soleimani M. Challenges in nursing continuing education: a qualitative study. Iran J Nurs Midwifery Res. 2015;20(3):378.

18. Monajati SF, Moradi A, Khayeri B. The relationship between InService Training for Nursing Staff Working in Isfahan Medical Sciences University Hospitals and occupational outcomes: organizational commitment, job satisfaction, and organizational citizenship behavior. Iran J Med Educ. 2014;14(6):495-506.

19. Awais Bhatti M, Kaur S. The role of individual and training design factors on training transfer. J Eur Ind Train. 2010;34(7):656-672. doi:10.1108/03090591011070770

20. Choi S, Cheung K, Pang S. Attributes of nursing work environment as predictors of registered nurses' job satisfaction and intention to leave. J Nurs Manag. 2013;21(3):429-439. doi:10.1111/jonm.2013. 21.issue-3

21. Lavasani M, Keyvanzade M, Arjmand N. Spirituality, job stress, organizational commitment, and job satisfaction among nurses in Tehran. J Contemp Psychol. 2008;3(2):61-73.

22. Mousazadeh S, Yektatalab S, Momennasab M, Parvizy S. Job satisfaction and related factors among Iranian intensive care unit nurses. BMC Res Notes. 2018;11(1):823. doi:10.1186/s13104-018-3913-5

23. Omar D, Omar KA, Kamaludin Z, Othman S, Yusoff ZM. Recreational facilities for youth in Malaysian urban areas case studies: Lembah Pantai, Kuala Lumpur and Kota Kinabalu, Sabah. Plan Malaysia J. 2017;15(2):66-74.

24. Aksoy Y, Çankaya S, Taşmektepligil MY. The Effects of Recreational and Sports Activities on Psychological Status in Young People Aged 11-13 Years. Univers J Public Health. 2017;5(5):217-221.

25. Roohi G, Hosseini A, Rahmani H, Mollaei E, Nasiri H. Distribution of workload and efficacy of nursing staff in internal medicine ward in a selected hospital of Golestan university of medical sciences. J Res Dev Nurs Midwifery. 2013;9(2):65-73.
26. Lee A, Cheung YSL, Joynt GM, Leung CCH, Wong W-T, Gomersall CD. Are high nurse workload/staffing ratios associated with decreased survival in critically ill patients? A cohort study. Ann Intensive Care. 2017;7(1):46. doi:10.1186/s13613-017-0269-2

27. Rivaz M, Momennasab M, Yektatalab S, Ebadi A. adequate resources as essential component in the nursing practice environment: a qualitative study. J Clin Diagn Res. 2017;11(6):IC01-IC4. doi:10.7860/ JCDR/2017/25349.9986

28. Murrells T, Robinson S, Griffiths P. Job satisfaction trends during nurses' early career. BMC Nurs. 2008;7(1):7. doi:10.1186/14726955-7-7

29. Atefi N, Lim Abdullah K, Wong LP, Mazlom R. Factors influencing job satisfaction among registered nurses: a questionnaire survey in Mashhad, Iran. J Nurs Manag. 2015;23(4):448-458. doi:10.1111/ jonm.2015.23.issue-4

30. Mastaneh Z, Mouseli L, Zamani M, et al. Investigation of nursing job satisfaction in university hospitals affiliated to Hormozgan University of Medical Sciences. Bimonthly J Hormozgan Univ Med Sci. 2014;18 (3):260-266.

31. Yıldız Z, Ayhan S, Erdoğmuş Ş. The impact of nurses' motivation to work, job satisfaction, and sociodemographic characteristics on intention to quit their current job: an empirical study in Turkey. Appl Nurs Res. 2009;22(2):113-118. doi:10.1016/j.apnr.2007.06.002

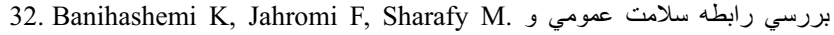
سبكى رهبري مديران و اثر آن بر رضايت شئ شغلي كاركنان در دانشعاه علوم بزشكي [Relationship Between General Health And Manager's Leadership Style And Its Effect On Staff's Job Satisfaction In Shiraz University Of Medical Sciences]. J Payavard Salamat. 1390;5(4):32-40

33. Bernardes A, G. Cummings G, Gabriel CS, Martinez EYD, Gomes MV, Coleman-Miller G. Implementation of a participatory management model: analysis from a political perspective. J Nurs Manag. 2015;23(7):888-897. doi:10.1111/jonm.12232

34. Mealer M, Conrad D, Evans J, et al. Feasibility and acceptability of a resilience training program for intensive care unit nurses. Am J Crit Care. 2014;23(6):e97-e105. doi:10.4037/ajcc2014747

35. Talasaz ZH, Saadoldin SN, Shakeri MT. Job Satisfaction and occupational stress in organizational commitment among midwives working in the maternity wards; Mashhad, Iran, 2014. Health Scope. 2017;6:1.

36. Li J, Lambert VA. Workplace stressors, coping, demographics and job satisfaction in Chinese intensive care nurses. Nurs Crit Care. 2008;13(1):12-24. doi:10.1111/j.1478-5153.2007.00252.x

37. Gorman T, Dropkin J, Kamen J, et al. Controlling health hazards to hospital workers: a reference guide. New Solut. 2014;23(1_suppl):1169. doi:10.2190/NS.23.Suppl

38. Rosnawati MR, Moe H, Masilamani R, Darus A. The Bahasa melayu version of the nursing stress scale among nurses: a reliability study in Malaysia. Asia Pac J Public Health. 2010;22(4):501-506. doi:10.1177/1010539510380560

39. Greenfield S, Parle J, Holder R. The anxieties of male and female medical students on commencing clinical studies: the role of gender. Educ Health. 2001;14(1):61-73. doi:10.1080/13576280010015371

40. Sh B, Kousha A, Janati A. Factors affecting nurses' job satisfaction: a systematic survey. Hakim Res J. 2012;15(2):130-139.

41. Habibzadeh H, Ahmadi F, Vanaki Z. Ethics in professional practice of Iranian nurses. Med Ethic History Med. 2010;3(5):26-36.

42. Wong KF, Yau SY. Nurses' experiences in spirituality and spiritual care in Hong Kong. Appl Nurs Res. 2010;23(4):242-244. doi:10.1016/j.apnr.2008.10.002

43. Zare A, Jahandideh S. The impact of special wards nursing spiritual well-being upon patients'spiritual care. Int J Nurs Res. 2014;3:30-38.

44. Hensel D, Middleton MJ, Engs RC. A cross-sectional study of drinking patterns, prelicensure nursing education, and professional identity formation. Nurse Educ Today. 2014;34(5):719-723. doi:10.1016/j.nedt.2013.08.018 
45. Mousazadeh S, Yektatalab S, Momennasab M, Parvizy S. Impediments to the formation of intensive care nurses' professional identify. Nurs Ethics. 2018;0969733018786059.

46. Levett-Jones T, Lathlean J. Belongingness: aprerequisite for nursing students' clinical learning. Nurse Educ Pract. 2008;8(2):103-111. doi:10.1016/j.nepr.2007.04.003
47. Sargent J, Williams RA, Hagerty B, Lynch-Sauer J, Hoyle K. Sense of belonging as a buffer against depressive symptoms. J Am Psychiatr Nurses Assoc. 2002;8(4):120-129. doi:10.1067/mpn.2002.127290

48. Baraz-Pordanjani SH, Memarian R, Vanaki Z. Damaged professional identity as a barrier to Iranian nursing students' clinical learning: a qualitative study. J Clin Nurs Midwifery. 2014;3(3):1-15.

\section{Publish your work in this journal}

Risk Management and Healthcare Policy is an international, peerreviewed, open access journal focusing on all aspects of public health, policy, and preventative measures to promote good health and improve morbidity and mortality in the population. The journal welcomes submitted papers covering original research, basic science, clinical \& epidemiological studies, reviews and evaluations, guidelines, expert opinion and commentary, case reports and extended reports. The manuscript management system is completely online and includes a very quick and fair peer-review system, which is all easy to use. Visit http://www.dovepress.com/testimonials.php to read real quotes from published authors. 